\title{
The neutrophil/lymphocyte ratio as a predictor of peritoneal metastasis during staging laparoscopy for advanced gastric cancer: a retrospective cohort analysis
}

\author{
Naohiko Nakamura ${ }^{1 *}$ (D), Shinichi Kinami ${ }^{1}$, Yoritaka Fujii ${ }^{1}$, Seiko Miura', Jun Fujita', Daisuke Kaida', Yasuto Tomita', \\ Takashi Miyata', Hideto Fujita', Nobuhiko Ueda', Yasuo lida² and Takeo Kosaka'
}

\begin{abstract}
Background: The use of staging laparoscopy (SL) has become widespread in patients with advanced gastric cancer (GC). This study aimed to evaluate the predictive value of the neutrophil/lymphocyte ratio (NLR) for the presence of peritoneal metastasis during staging laparoscopy in patients with advanced GC.

Methods: This retrospective analysis was performed in 35 patients with advanced GC who underwent SL at Kanazawa Medical University Hospital between January 2009 and December 2017. Clinicopathological characteristics were examined and multivariate analyses were performed to identify preoperative laboratory parameters that were independently associated with the presence of peritoneal metastasis or cytological malignancy (P/CY positive) during SL.

Results: A P/CY-positive result was confirmed during SL in 16 patients (45.7\%). Patients with type 4 or diffuse type 3 tumors showed a significantly higher $\mathrm{P} / \mathrm{CY}$-positive rate than those with other tumor types (58.3\% vs. $18.2 \%, P=0.02)$. In the univariate analysis for preoperative laboratory parameters, NLR $(P<0.0001)$ and total protein $(P=0.03)$ and albumin $(P=0.04)$ levels were significantly correlated with a P/CY-positive result. On multivariate analysis, NLR was significantly correlated with a $P / C Y$-positive result $(P=0.0002)$. In patients with type 4 or diffuse type 3 tumors, a high NLR $(>3.5)$ was associated with a significantly higher P/CY-positive rate than a low NLR $(\leq 3.5)(83.3 \%$ vs. $33.3 \%, P=0.01)$. Moreover, in patients without type 4 or diffuse type 3 tumors, the P/CY-positive rates were $100 \%$ and $0 \%$ in patients with NLR> 3.5 and NLR $\leq 3.5$, respectively.

Conclusions: The preoperative NLR was a significant independent predictor of the presence of peritoneal metastasis during SL. Regardless of tumor type, patients with a high NLR could be reasonable candidates for SL. On the other hand, non-diffuse type tumor accompanied by a low NLR may not need to undergo SL.
\end{abstract}

Keywords: Gastric cancer, Staging laparoscopy, Neutrophil/lymphocyte ratio

\section{Background}

Gastric cancer (GC) is the fifth most common malignancy and the second most common cause of cancer mortality worldwide [1]. The curative treatment for advanced GC consists of gastrectomy with perioperative chemotherapy in Western countries [2,3]. Even in stage IV GC, curative resection by conversion gastrectomy

\footnotetext{
* Correspondence: n1982422@kuhp.kyoto-u.ac.jp

'Department of Surgical Oncology, Kanazawa Medical University Hospital, 1-1

Daigaku, Uchinada, Kahoku, Ishikawa 920-0293, Japan

Full list of author information is available at the end of the article
}

following systemic chemotherapy could improve the prognosis [4]. In such an advanced stage of GC, accurate evaluation of peritoneal metastasis is essential for providing optimal treatment because the GCs in most patients who have exhibited peritoneal metastasis are not suitable for curative resection by gastrectomy. Several imaging methods are employed in the staging of GC. A recent meta-analysis showed that computed tomography has good accuracy in staging GC, but the detection of peritoneal metastasis remains to have low sensitivity and specificity [5]. In these situations, staging laparoscopy

(c) The Author(s). 2019 Open Access This article is distributed under the terms of the Creative Commons Attribution 4.0 International License (http://creativecommons.org/licenses/by/4.0/), which permits unrestricted use, distribution, and 
(SL) has played a cardinal role in the investigation of treatment strategies for patients with advanced GC in recent years [6].

SL for GC has been particularly used in patients with locally advanced GC, candidates for neoadjuvant therapy, and those suspected with peritoneal metastasis [7]. Several studies have demonstrated the superiority of SL over conventional imaging tests for detecting peritoneal metastasis $[8,9]$. Although indicating SL based on preoperative clinicopathological factors is still controversial, patients with type 4 or diffuse-type tumors could have a high potential for peritoneal disease spread and be considered as moresuitable candidates for SL $[10,11]$. However, SL is an invasive procedure and is accompanied by a risk of adverse events for the patients. Additionally, SL should not be recommended on a routine basis because of its cost. Therefore, noninvasive clinical parameters that can predict the presence of peritoneal metastasis are urgently needed to avoid unnecessary laparoscopy.

In recent years, there is a rapidly growing interest in the association between the neutrophil/lymphocyte ratio (NLR) and the clinical outcomes of upper gastrointestinal cancers. A retrospective analysis of GC patients who underwent gastrectomy has observed an association between a high NLR and poor survival, tumor depth, and peritoneal metastasis [12]. The NLR is calculated as the neutrophil count divided by the lymphocyte count and is easily measurable in a routine preoperative examination for GC patients. Thus, we conceived that the preoperative NLR could help in narrowing down the selection of candidates for SL. In this context, this study aimed to evaluate the predictive value of the NLR for the presence of peritoneal metastasis or cytological malignancy $(\mathrm{P} / \mathrm{CY}$ positive) during SL in patients with advanced GC.

\section{Materials and methods Patients}

This retrospective analysis was performed in 35 patients with advanced GC who underwent SL at Kanazawa Medical University Hospital between January 2009 and December 2017. For the clinical staging for GC, all the patients underwent abdominal computed tomography scan and positron emission tomography. The candidates for SL in this study were patients with advanced gastric cancer who were suspected to have peritoneal or severe lymph node metastasis during the preoperative imaging examination or who were shown to exhibit type 4 or diffuse-type tumors on upper gastrointestinal endoscopy. In addition to these findings, during the preoperative examinations, we performed SL in patients who could potentially undergo curative resection or neoadjuvant chemotherapy, if peritoneal metastasis was not detected through the SL. We obtained informed consent from the patients. This study was approved by the Medicine Ethics Committee of Kanazawa Medical University.

\section{Clinicopathological evaluations}

Data on clinical characteristics, gender, age, and body mass index were extracted from our hospital's database. The tumors of all patients were histologically confirmed as adenocarcinomas and clinically staged according to the 7th edition of the American Joint Committee on Cancer (AJCC) [13] based on tumor location, macroscopic tumor type, depth of tumor invasion (T), extent of lymph node metastasis $(\mathrm{N})$, and distant metastasis $(\mathrm{M})$. We defined type $3 \mathrm{GC}$ that was located from the upper to lower stomach as diffuse type 3 tumor. We collected the results of the blood examination before SL, including white blood cell (WBC) count, fraction of neutrophils and lymphocytes in WBC differentiation, NLR, hemoglobin level, serum platelet count, and levels of $\mathrm{C}$-reactive protein (CRP), total protein (TP), albumin, cholinesterase, carcinoembryonic antigen (CEA), carbohydrate antigen 19-9 (CA19-9), and carbohydrate antigen 125 (CA125).

\section{Surgical procedures and pathological evaluations}

SL was performed as follows by gastrointestinal surgeons: (1) a small subumbilical incision was made, and a $12-\mathrm{mm}$ trocar was inserted; (2) $50-100 \mathrm{ml}$ of saline was used to irrigate the pouch of Douglas and then was aspirated for cytological examination; (3) the visible surface of the stomach, liver, diaphragm, omentum, and peritoneum was systematically explored in search of malignant deposits. In case of suspicious macroscopic lesions, biopsies were performed and sent for histological review. A P/CY-positive result was defined when peritoneal dissemination or presence of adenocarcinoma cells in the cytology specimens was histologically confirmed by pathologists.

\section{Statistical analysis}

Data were expressed as $n$ (\%) or medians (range). Continuous variables were compared using Student's $t$ test, while categorical variables were compared using the $\chi^{2}$ test. All $P$ values were two-sided, and differences with a $P$ value of $<0.05$ were considered statistically significant. A logistic regression model was used to identify clinical factors that were independently associated with a $\mathrm{P} / \mathrm{CY}$ positive result. Variables that were associated with a $\mathrm{P} /$ CY-positive result at $P \leq 0.10$ in the univariate analysis were included in the multivariate analysis. The diagnostic performance of the NLR with regard to the P/CYpositive rate was evaluated using multivariate receiver operating characteristic (ROC) curve analysis. All statistical analyses were performed using JMP software version 8.0 (SAS Institute, Cary, NC, USA). 


\section{Results}

\section{Patient characteristics}

The median age of the study population was 66.5 years, and approximately two thirds of patients were male (Table 1). Before SL, the median value of the NLR was 2.3. Preoperative examinations indicated that $88.6 \%$ of patients had type 3 or 4 GC, $80.0 \%$ had cT4 disease, and $51.4 \%$ had diffusetype tumors. The proportion of patients who were clinically diagnosed with stage IV disease was $34.4 \%$. Among 28 patients who were clinically diagnosed as not having peritoneal metastasis before SL, 10 (35.7\%) were surgically evaluated as $\mathrm{P} / \mathrm{CY}$ positive during SL (Table 2). Among patients who were clinically suspected with peritoneal metastasis, $85.7 \%$ were confirmed P/CY positive by SL. Only one patient was $\mathrm{P} / \mathrm{CY}$ negative during SL despite being suspected with peritoneal metastasis during the preoperative examination.

\section{Proportion of $\mathrm{P} / \mathrm{CY}$-positive patients according to clinical features of GC}

The correlation between the $\mathrm{P} / \mathrm{CY}$-positive rates at SL and the clinical stage or microscopic tumor type in the

Table 1 Patient characteristics

\begin{tabular}{|c|c|}
\hline & $n=35$ \\
\hline Gender (male) & $23(65.7 \%)$ \\
\hline Age & $69(30-86)$ \\
\hline BMI & $20.9(15.5-30.9)$ \\
\hline White blood cell $(\mu \mathrm{l})$ & $6340(3140-12,960)$ \\
\hline Neutrophil $(\mu \mathrm{l})$ & $4150(1380-10,640)$ \\
\hline Lymphocyte $(\mu l)$ & $1310(690-3220)$ \\
\hline NLR & $2.3(0.8-7.6)$ \\
\hline Hemoglobin (g/dl) & $12.2(7.3-15.7)$ \\
\hline Platelet count $\left(\times 10^{4} / \mu \mathrm{l}\right)$ & $29.6(13.1-61.4)$ \\
\hline CRP $(\mathrm{mg} / \mathrm{dl})$ & $0.1(0.1-13.5)$ \\
\hline Total protein (g/dl) & $6.7(4.5-8.2)$ \\
\hline Albumin (g/dl) & $3.8(2.1-4.4)$ \\
\hline Cholinesterase (U/I) & $240(107-410)$ \\
\hline CEA (ng/ml) & $2.4(0.5-1380)$ \\
\hline CA19-9 (U/ml) & $19.8(0.5-159.5)$ \\
\hline CA125 (U/ml) & $11.5(4.0-247.3)$ \\
\hline Tumor differentiation (poorly or signet) & $10(28.6)$ \\
\hline Tumor type $(3,4)$ & $31(88.6 \%)$ \\
\hline Tumor location (UML) & $18(51.4 \%)$ \\
\hline$T 4^{\mathrm{a}}$ & $28(80.0 \%)$ \\
\hline$N>2^{a}$ & $18(51.4 \%)$ \\
\hline clinical Stage II/III/IV ${ }^{a}$ & $7(20.0 \%) / 16(45.7 \%) / 12(34.3 \%)$ \\
\hline
\end{tabular}

Values are in $n$ (\%) or medians (range)

${ }^{\mathrm{a}} 7$ th edition of the American Joint Committee on Cancer (AJCC) [13]

$B M I$, Body mass index; NLR, neutrophil/lymphocyte ratio; $C R P, C$-reactive protein; CEA, carcinoembryonic antigen; CA19-9, carbohydrate antigen 19-9; CA125, carbohydrate antigen 125
Table 2 Clinical and surgical diagnoses for peritoneal metastasis of cancer

\begin{tabular}{lll}
\hline & $\begin{array}{l}\text { Preoperative peritoneal } \\
\text { metastasis }(+) \\
(n=28)\end{array}$ & $\begin{array}{l}\text { Preoperative peritoneal } \\
\text { metastasis }(-) \\
(n=7)\end{array}$ \\
\hline $\begin{array}{l}\mathrm{P} \text { and CY negative at } \\
\mathrm{SL}\end{array}$ & $18(64.3 \%)$ & $1(14.3 \%)$ \\
$\mathrm{P}$ or CY positive at SL & $10(35.7 \%)$ & $6(85.7 \%)$ \\
\hline
\end{tabular}

Values are in $n(\%)$

$S L$, staging laparoscopy; $P$, peritoneal metastasis; $C Y$, cytology

preoperative examinations was analyzed (Table 3). In patients with type 4 or diffuse type $3 \mathrm{GC}, 58.3 \%$ were P/ $\mathrm{CY}$ positive during SL, and the proportion was significantly higher than that in patients with other tumor types $(58.3 \%$ vs. $18.2 \%, P=0.02)$. Meanwhile, there was no significant difference in $\mathrm{P} / \mathrm{CY}$-positive rates between clinical $\mathrm{T}$ and $\mathrm{N}$ factors.

\section{Correlation between preoperative parameters and P/CY- positive results}

Univariate analysis showed that the NLR $(P<0.0001)$, TP $(P=0.03)$, albumin $(P=0.04)$ levels, and type 4 or diffuse type $3 \mathrm{GC}(P=0.02)$ were significantly correlated with a P/CY-positive result during SL (Table 4). The P/ CY-positive rates were $85.7 \%, 66.7 \%, 75.0 \%$, and $58.3 \%$ in patients with NLR $>3.5$, TP $<6.5 \mathrm{~g} / \mathrm{dl}$, albumin $<3.5 \mathrm{~g} / \mathrm{dl}$, and type 4 or diffuse type $3 \mathrm{GC}$, respectively. Multivariate analysis showed that NLR was significantly correlated with a $\mathrm{P} / \mathrm{CY}$-positive result $(P=0.0006)$. On the other hand, there was no significant difference in the predictive values of the tumor markers CEA, CA19-9, and CA125. Among patients who were not diagnosed with peritoneal metastasis in the preoperative examinations, the $\mathrm{P} / \mathrm{CY}$-positive rates were $80 \%$ and $11.1 \%$ in patients

Table 3 Correlation between the preoperative-clinical features of GC and the P/CY-positive rates

\begin{tabular}{lll}
\hline & P/CY positive & $P$ value \\
\hline Clinical T & & \\
$\mathrm{T} 3 \geqq(n=7)$ & $2(28.6 \%)$ & 0.31 \\
$\mathrm{~T} 4(n=28)$ & $14(50.0 \%)$ & \\
Clinical $N^{\mathrm{a}}$ & & \\
$\mathrm{N} 1 \geqq(n=17)$ & $10(58.8 \%)$ & 0.13 \\
$\mathrm{~N} 2 \leqq(n=18)$ & $6(33.3 \%)$ & \\
Macroscopic tumor type & & \\
Others $(n=11)$ & $2(18.2 \%)$ & 0.02 \\
Type 4 or diffuse type 3 $(n=24)$ & $14(58.3 \%)$ & \\
Presence of paraaortic lymph node metastasis & 0.50 \\
$(-)(n=29)$ & $14(48.3 \%)$ & \\
$(+)(n=6)$ & $2(33.3 \%)$ & \\
\hline
\end{tabular}

Values are in $n$ (\%)

${ }^{a} 7$ th edition of the American Joint Committee on Cancer (AJCC) [13]

$G C$, gastric cancer; $P / C Y$, peritoneal metastasis or cytological malignancy 
Table 4 Univariate and multivariate analyses to identify preoperative predictors of peritoneal metastasis

\begin{tabular}{|c|c|c|c|c|}
\hline \multirow{3}{*}{ Age (> 70 years old $)$} & \multicolumn{2}{|c|}{ Univariate analyses } & \multicolumn{2}{|c|}{ Multivariate analyses } \\
\hline & Odds ratio & $P$ value & Odds ratio & $P$ value \\
\hline & 2.2 & 0.27 & & \\
\hline Gender (male) & 0.5 & 0.28 & & \\
\hline $\mathrm{BMI}(<20)$ & 2.2 & 0.28 & & \\
\hline White blood cell $(>7000 / \mu l)$ & 0.6 & 0.51 & & \\
\hline $\operatorname{NLR}(>3.5)$ & 25.5 & $<0.0001$ & 25.9 & 0.0006 \\
\hline Platelet count $\left(<30 \times 10^{4} / \mu \mathrm{l}\right)$ & 1.2 & 0.83 & & \\
\hline Hemoglobin $(<12 \mathrm{~g} / \mathrm{dl})$ & 1.7 & 0.43 & & \\
\hline CRP (> $1 \mathrm{mg} / \mathrm{dl})$ & 4.2 & 0.21 & & \\
\hline Total protein $(<6.5 \mathrm{~g} / \mathrm{dl})$ & 4.7 & 0.03 & 7.8 & 0.08 \\
\hline Albumin $(<3.5 \mathrm{~g} / \mathrm{dl})$ & 5.1 & 0.04 & 2.8 & 0.53 \\
\hline Cholinesterase (<240 U/I) & 1.1 & 0.88 & & \\
\hline CEA (> $5 \mathrm{ng} / \mathrm{ml})$ & 1.1 & 0.93 & & \\
\hline CA19-9 (> $37 \mathrm{U} / \mathrm{ml})$ & 2.2 & 0.28 & & \\
\hline CA125 (> $35 \mathrm{U} / \mathrm{ml})$ & 3.9 & 0.12 & & \\
\hline Type 4 or diffuse type 3 & 6.3 & 0.02 & 5.6 & 0.13 \\
\hline $\mathrm{T} 4^{\mathrm{a}}$ & 2.5 & 0.30 & & \\
\hline $\mathrm{N} 2 \leqq \mathrm{a}$ & 0.35 & 0.13 & & \\
\hline Stage IV ${ }^{a}$ & 2.2 & 0.29 & & \\
\hline
\end{tabular}

BMI, Body mass index; NLR, neutrophil/lymphocyte ratio; CRP, C-reactive protein; CEA, carcinoembryonic antigen; CA19-9, carbohydrate antigen 19-9; CA125, carbohydrate antigen 125

${ }^{\mathrm{a}}$ 7th edition of the American Joint Committee on Cancer (AJCC) [13]

with NLR $>3.5$ and NLR $\leq 3.5$, respectively $(P=0.003)$. In patients with type 4 or diffuse type 3 tumors, the $\mathrm{P} / \mathrm{CY}$-positive rates were $83.3 \%$ and $33.3 \%$ in those with NLR $>3.5$ and $\mathrm{NLR} \leq 3.5$, respectively (Fig. 1). Moreover, in patients without type 4 or diffuse type 3 tumors, the $\mathrm{P} / \mathrm{CY}$-positive rates were $100 \%$ and $0 \%$ in those with NLR $>3.5$ and NLR $\leq 3.5$, respectively. The area under the ROC curve of the NLR between the $\mathrm{P} / \mathrm{CY}$-positive and $\mathrm{P} / \mathrm{CY}$-negative results was 0.86 (Fig. 2). The best cutoff point of the NLR for distinguishing a P/CY-positive result was 3.7. At this cutoff point, the sensitivity and specificity were 0.75 and 0.89 , respectively.

\section{Discussion}

Since the 1990s, SL has been performed for patients with resectable advanced GC, with a reported detection rate of metastatic disease of $21-31 \%[14,15]$. The use of SL has become widespread, but recently, its optimal indication restricts it to patients with a high risk of metastatic disease [16-18]. Such selective strategy can help avoid unnecessary laparoscopy for patients with resectable tumors and prevent potential complications of SL. Previously, patients with large infiltrating type 3 and type 4 tumors were reported as reasonable candidates

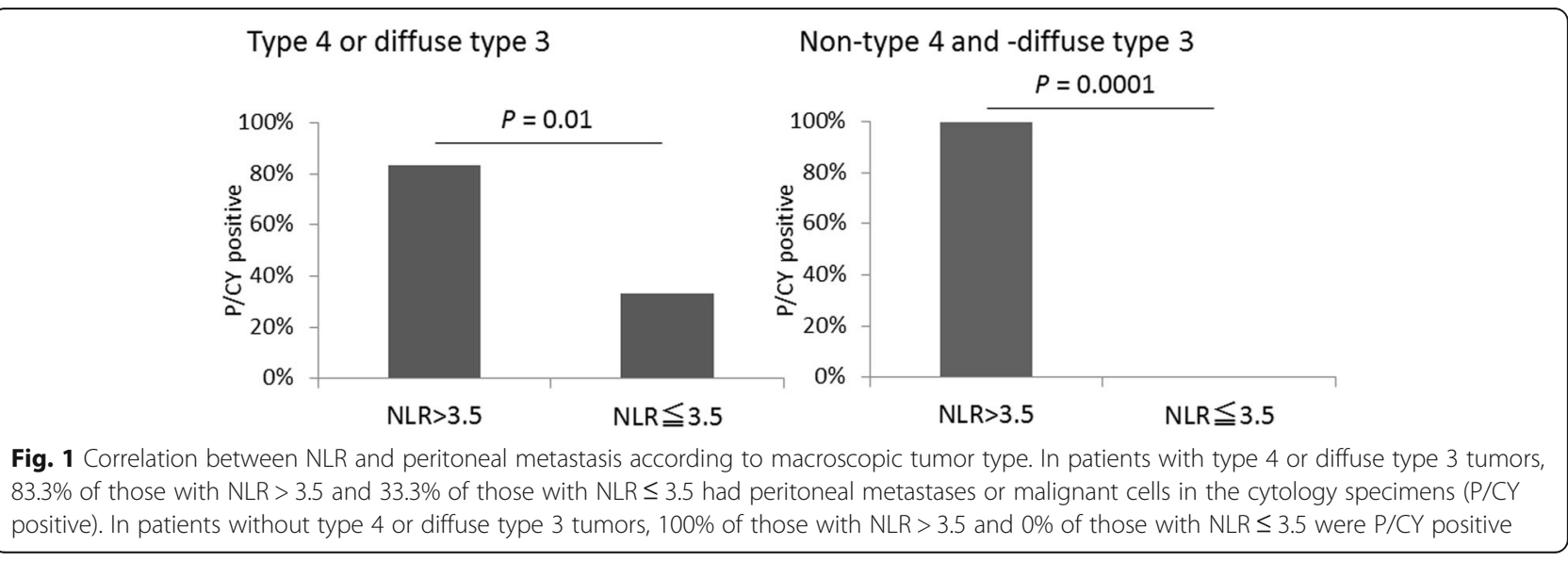




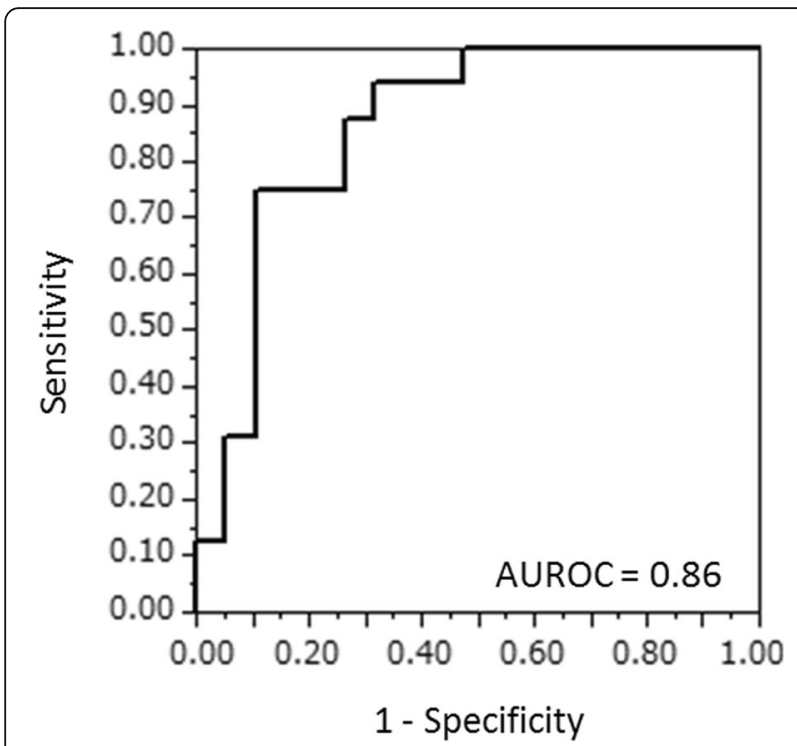

Fig. 2 Diagnostic performance of NLR was evaluated by multivariate receiver operating characteristic $(\mathrm{ROC})$. The area under the $\mathrm{ROC}$ curve (AUROC) of the NLR between the P/CY-positive and P/CYnegative results was 0.86 . The best cutoff point of NLR was 3.7

for SL $[10,11,18]$. In our results, patients with type 4 or diffuse type 3 tumors showed higher P/CY-positive rates during SL. On the other hand, patients with clinical T4 tumors can be recommended to undergo SL [19]. Although there was no significant difference in $\mathrm{P} / \mathrm{CY}$-positive rate between $\mathrm{T} 4$ tumors and $\mathrm{T} 3 \geq$ tumors in our study, patients with T4 tumors tended to show higher P/ CY-positive rates. The clinicopathological features of tumors are essential to deciding the indications for SL. However, the indication using preoperative laboratory parameters along with clinicopathological features has not been previously proposed. Here, we found that a higher NLR was significantly associated with a P/CYpositive result during SL. Combining the NLR and macroscopic tumor type could be more helpful in adjusting the selection of candidates for SL.

Recently, the NLR has been reported as a significant independent predictor of the presence of peritoneal metastasis in patients with advanced GC [20], and such finding is consistent with our results. The predictive value of the NLR for peritoneal metastasis during SL has been investigated in early gastric cancer or lower esophageal cancer, but not in advanced GC [21]. In our study, we demonstrated that a high NLR was a significant independent predictor of a $\mathrm{P} / \mathrm{CY}$-positive result during SL in patients with advanced GC. Most importantly, we found that preoperative NLR was associated with peritoneal disease spread regardless of tumor type. Although the macroscopic tumor features or severity of tumor invasion in preoperative examinations are very important for deciding the indication for SL, the NLR could be a supplemental criteria to decide whether SL is performed. In contrast, among patients with a low NLR without type 4 or diffuse type 3 tumors, none exhibited a P/CY-positive result. This result may suggest that patients with a low NLR without type 4 or diffuse type 3 tumors do not need to undergo SL for the evaluation of peritoneal metastasis and should be immediately planned for curative operation or neoadjuvant chemotherapy. Combining macroscopic tumor features and the NLR could be a promising strategy in further reducing the number of candidates for SL. Furthermore, we demonstrated the optimal cutoff value of the NLR to be 3.7, which is higher than the value in previous reports analyzing the predictive values of the NLR for the prognosis of GC $[22,23]$. It might be reasonable that the cutoff value was set higher to predict peritoneal disease spread because our cohort consisted of the patients with more advanced GC who were indicated for SL. In the future, the optimal cutoff value for predicting peritoneal metastasis should be validated in a prospective study.

The NLR is a simple index of the systemic inflammatory response [24, 25]. Previously, several studies have reported that laboratory parameters reflecting inflammation, such as the NLR and serum CRP level, may be related to the prognosis of cancer, for example, GC, colorectal cancer, and lung cancer [12, 24, 26, 27]. Although it is unclear why the NLR could be elevated in cancer with a poor prognosis, these results suggest the existence of a close relationship between inflammation and cancer progression. Among inflammatory parameters, elevated serum levels of interleukin 6 (IL-6) but not CRP were reported to be associated with the presence of peritoneal metastasis in GC patients [28]. It was also reported that the interaction of neutrophils with tumor cells promoted GC cell migration and invasion through a pathway involving IL-6 [29]. Therefore, an increased neutrophil count may be attributed to an upregulation of IL-6 due to peritoneal disease progression. On the other hand, the immune response of the hosts to tumors depends on the lymphocytes [30], and an increased number of neutrophils suppresses the cytolytic activity of the lymphocytes [31, 32]. Considering these results, an increased neutrophil count and a decreased immune response to tumors may be related to the mechanism of peritoneal metastasis progression, and an increased NLR may reflect these conditions.

This study has certain limitations. It was a retrospective study performed at a single institution; additionally, the sample size was very small. Although we indicated that the NLR could have a strong potential as a predictor for the presence of peritoneal metastasis during SL, the current study lacks statistical strength due to the small sample size. In order to overcome the shortcomings of this study and confirm the predictive value of the 
NLR, we should perform a prospective cohort study in multiple institutions

\section{Conclusions}

We found that the high preoperative NLR was associated with the presence of peritoneal metastasis during SL in patients with advanced GC. When adjusting the indication for SL, the NLR could be useful as an adjunct to the decision of criteria for SL by combining it with macroscopic tumor features.

\section{Abbreviations}

CA125: Carbohydrate antigen; CA19-9: Carbohydrate antigen 19-9;

CEA: Carcinoembryonic antigen; CRP: C-reactive protein; GC: Gastric cancer; IL-6: Interleukin 6; NLR: Neutrophil/lymphocyte ratio; ROC: Receiver operating characteristic; SL: Staging laparoscopy; TP: Total protein; WBC: White blood cell

\section{Acknowledgements}

Not applicable

\section{Authors' contributions}

NN, SK, and TK designed the study. NN, YF, SM, JF, DK, YT, and TM performed data acquisition. NN, YI, YF, SM, JF, DK, YT, and TM performed data analysis and interpretation. NN and SK prepared the manuscript. SK, HF, NU, and TK revised the paper critically. All authors read and approved the final manuscript.

\section{Funding}

None

\section{Availability of data and materials}

All data are available without restriction. Researchers can obtain data by contacting the corresponding author.

\section{Ethics approval and consent to participate}

This study was approved by the Medicine Ethics Committee of Kanazawa Medical University. The research reported in this paper was in compliance with the Helsinki Declaration.

\section{Consent for publication}

We obtained informed consent from the patients.

\section{Competing interests}

The authors declare that they have no competing interests.

\section{Author details}

'Department of Surgical Oncology, Kanazawa Medical University Hospital, 1-1 Daigaku, Uchinada, Kahoku, Ishikawa 920-0293, Japan. ${ }^{2}$ Department of Mathematics, Division of General Education, Kanazawa Medical University Hospital, 1-1 Daigaku, Uchinada, Kahoku, Ishikawa 920-0293, Japan.

Received: 3 April 2019 Accepted: 19 June 2019

Published online: 25 June 2019

\section{References}

1. Ferlay J, Soerjomataram I, Dikshit R, Eser S, Mathers C, Rebelo M, et al. Cancer incidence and mortality worldwide: sources, methods and major patterns in GLOBOCAN 2012. Int J Cancer. 2015;136:E359-86.

2. Cunnimgham D, Allum WH, Stenning SP, Thompson JN, Van de Velde CJ, Nicolson M, et al. MAGIC trial participants. Perioperative chemotherapy versus surgery alone for resectable gastroesophageal cancer. N Engl J Med. 2006;355:11-20.

3. Brenkman HJ, Haverkamp L, Ruurda JP, van Hillegersberg R. Worldwide practice in gastric cancer surgery. World J Gastroenterol. 2016;22:4041-8.

4. Han DS, Suh YS, Kong SH, Lee HJ, Im SA, Bang YJ, et al. Outcomes of surgery aiming at curative resection in good responder to induction chemotherapy for gastric cancer with distant metastases. J Surg Oncol. 2013;107:511-6

5. Seevaratnam R, Cardoso R, McGregor C, Lourenco L, Mahar A, Sutradhar R, et al. How useful is preoperative imaging for tumor, node, metastasis (TNM) staging of gastric cancer? A meta-analysis. Gastric Cancer. 2012;15:S3-18.

6. Machairas $N$, Charalampoudis $P$, Molmenti EP, Kykalos S, Tsaparas $P$, Stamopoulos $\mathrm{P}$, et al. The value of staging laparoscopy in gastric cancer. Ann Gastroenterol. 2017:30:287-94.

7. Song KY, Kim JJ, Kim SN, Park CH. Staging laparoscopy for advanced gastric cancer: is it also useful for the group which has an aggressive surgical strategy? World J Surg. 2007;31:1228-33.

8. Burbidge S, Mahady K, Naik K. The role of CT and staging laparoscopy in the staging of gastric cancer. Clin Radiol. 201(68):251-5.

9. Blackshaw GR, Barry JD, Edwards P, Allison MC, Thomas GV, Lewis WG. Laparoscopy significantly improves the perceived preoperative stage of gastric cancer. Gastric Cancer. 2003;6:225-9.

10. Hosogi H, Shinohara H, Tsunoda S, Hisamori S, Sumida H, Hida K, et al. Staging laparoscopy for advanced gastric cancer: significance of preoperative clinicopathological factors. Langenbecks Arch Surg. 2017:402:33-9.

11. Miki Y, Tokunaga M, Tanizawa Y, Bando E, Kawamura T, Terashima M. Staging Laparoscopy for patients with cM0, type 4, and large type 3 gastric cancer. World J Surg. 2015;39:2742-7.

12. Shimada $H$, Takiguchi $N$, Kainuma $O$, Soda H, Ikeda A, Cho A, et al. High preoperative neutrophil-lymphocyte ratio predicts poor survival in patients with gastric cancer. Gastric Cancer. 2010;13:170-6.

13. Edge SB, Compton CC. The American Joint Committee on Cancer: the 7th edition of the AJCC cancer staging manual and the future of TNM. Ann Surg Oncol. 2010;17:1471-4

14. Hawley JA, Burke LM. Laparoscopy in the management of gastric adenocarcinoma. Ann Surg. 1997:225:262-7.

15. D'Ugo DM, Persiani R, Caracciolo F, Ronconi P, Coco C, Picciocchi A. Selection of locally advanced gastric carcinoma by preoperative staging laparoscopy. Surg Endosc. 1997;11:1159-62.

16. Sarela Al, Lefkowitz R, Brennan MF, Karpeh MS. Selection of patients with gastric adenocarcinoma for laparoscopic staging. Am J Surg. 2006;191:134-8.

17. Yano M, Tsujinaka $T$, Shiozaki $H$, Inoue $M$, Sekimoto $M$, Doki $Y$, et al. Appraisal of treatment strategy by staging laparoscopy for locally advanced gastric cancer. World J Surg. 2000:24:1130-5.

18. Shimizu H, Imamura H, Ohta K, Miyazaki Y, Kishimoto T, Fukunaga M, et al. Usefulness of staging laparoscopy for advanced gastric cancer. Surg Today. 2010:40:119-24.

19. Tsuchida K, Yoshikawa T, Tsuburaya A, Cho H, Kobayashi O. Indications for staging laparoscopy in clinical T4 M0 gastric cancer. World J Surg. 2011;35:2703-9.

20. Nakayama Y, Gotohda N, Shibasaki H, Nomura S, Kinoshita T, Hayashi R. Usefulness of the neutrophil/lymphocyte ratio measured preoperatively as a predictor of peritoneal metastasis in patients with advanced gastric cancer. Surg Today. 2014:44:2146-52.

21. Grenader T, Plotkin Y, Mohammadi B, Dawas K, Hashemi M, Mughal M, et al Predictive value of the neutrophil/lymphocyte ratio in peritoneal and/or metastatic disease at staging laparoscopy for gastric and esophageal adenocarcinoma. J Gastrointest Cancer. 2015:46:267-71.

22. Jung MR, Park YK, Jeong O, Seon JW, Ryu SY, Kim DY, et al. Elevated preoperative neutrophil to lymphocyte ratio predicts poor survival following resection in late stage gastric cancer. J Surg Oncol. 2011;104:504-10.

23. Yamanaka T, Matsumoto S, Teramukai S, Ishiwata $R$, Nagai $Y$, Fukushima M. The baseline ratio of neutrophils to lymphocytes is associated with patient prognosis in advanced gastric cancer. Oncology. 2007:73:215-20.

24. Walsh SR, Cook EJ, Goulder F, Justin TA, Keeling NJ. Neutrophil-lymphocyte ratio as a prognostic factor in colorectal cancer. J Surg Oncol. 2005;91:181-4

25. Zahorec R. Ratio of neutrophil to lymphocyte counts--rapid and simple parameter of systemic inflammation and stress in critically ill. Bratisl Lek Listy. 2001;102:5-14.

26. Nozoe T, Mori E, Takahashi I, Ezaki T. Preoperative elevation of serum Creactive protein as an independent prognostic indicator of colorectal carcinoma. Surg Today. 2008;38:597-602.

27. Tomita M, Shimizu T, Ayabe T, Yonei A, Onitsuka T. Preoperative neutrophil to lymphocyte ratio as a prognostic predictor after curative resection for non-small cell lung cancer. Anticancer Res. 2011:31:2995-8.

28. Kim DK, Oh SY, Kwon HC, Lee S, Kwon KA, Kim BG, et al. Clinical significances of preoperative serum interleukin-6 and C-reactive protein level in operable gastric cancer. BMC Cancer. 2009;9:155. 
29. Zhang W, Gu J, Chen J, Zhang P, Ji R, Qian H, et al. Interaction with neutrophils promotes gastric cancer cell migration and invasion by inducing epithelial-mesenchymal transition. Oncol Rep. 2017;38:2959-66.

30. Halazun K, Aldoori A, Malik HZ, Al-Mukhtar A, Prasad KR, Toogood GJ, et al. Elevated preoperative neutrophil to lymphocyte ratio predicts survival following hepatic resection for colorectal liver metastases. Eur J Surg Oncol. 2008; $34: 55-60$

31. Petrie HT, Klassen LW, Kay HD. Inhibition of human cytotoxic T lymphocyte activity in vitro by autologous peripheral blood granulocytes. J Immunol. 1985;134:230-4.

32. el-Hag A, Clark RA. Immunosuppression by activated human neutrophils. Dependence on the myeloperoxidase system. J Immunol. 1987;139:2406-13.

\section{Publisher's Note}

Springer Nature remains neutral with regard to jurisdictional claims in published maps and institutional affiliations.

Ready to submit your research? Choose BMC and benefit from:

- fast, convenient online submission

- thorough peer review by experienced researchers in your field

- rapid publication on acceptance

- support for research data, including large and complex data types

- gold Open Access which fosters wider collaboration and increased citations

- maximum visibility for your research: over $100 \mathrm{M}$ website views per year

At BMC, research is always in progress.

Learn more biomedcentral.com/submissions 